\title{
Clinical trials using mesenchymal stem cells in liver diseases and inflammatory bowel diseases
}

\author{
Atsunori Tsuchiya*, Yuichi Kojima, Shunzo Ikarashi, Satoshi Seino, Yusuke Watanabe, Yuzo Kawata and Shuji Terai
}

\begin{abstract}
Mesenchymal stem cell (MSC) therapies have been used in clinical trials in various fields. These cells are easily expanded, show low immunogenicity, can be acquired from medical waste, and have multiple functions, suggesting their potential applications in a variety of diseases, including liver disease and inflammatory bowel disease. MSCs help prepare the microenvironment, in response to inflammatory cytokines, by producing immunoregulatory factors that modulate the progression of inflammation by affecting dendritic cells, B cells, T cells, and macrophages. MSCs also produce a large amount of cytokines, chemokines, and growth factors, including exosomes that stimulate angiogenesis, prevent apoptosis, block oxidation reactions, promote remodeling of the extracellular matrix, and induce differentiation of tissue stem cells. According to ClinicalTrials.gov, more than 680 clinical trials using MSCs are registered for cell therapy of many fields including liver diseases (more than 40 trials) and inflammatory bowel diseases (more than 20 trials). In this report, we introduce background and clinical studies of MSCs in liver disease and inflammatory bowel diseases.
\end{abstract}

Keywords: Mesenchymal stem cell, Liver disease, Inflammatory bowel disease, Cell therapy

\section{Background}

The digestive system, which consists of the gastrointestinal tract, liver, pancreas, and biliary tree, functions in digestion, absorption, and metabolism and affects the basis of life. Various diseases, including cancer, inflammatory disease, infection, stones, and ulcers, are studied under the context of gastroenterology. While innovative drugs against Helicobacter pylori [1], hepatitis C virus [2], and inflammatory bowel disease (IBD) [3] have recently been developed, there are still unmet needs in this field, including in acute and chronic liver failure and refractory IBDs. Cell therapy may fulfill these unmet needs, and cell therapies using mesenchymal stem cells (MSCs) have become a major focus in many fields [4]. MSCs are reported to have multiple functions, especially anti-fibrosis and antiinflammatory effects are focused in acute and chronic liver failure and refractory IBDs. Furthermore, MSCs have low immunogenicity, can expand easily, and can be obtained from medical waste, suggesting their potential to expand

\footnotetext{
* Correspondence: atsunori@med.niigata-u.ac.jp
Division of Gastroenterology and Hepatology, Graduate School of Medica

* Correspondence: atsunori@med.niigata-u.ac.jp

* Correspondence: atsunori@med.niigata-u.ac.jp
Division of Gastroenterology and Hepatology, Graduate School of Medical
and Dental Science, Niigata University, 1-757 Asahimachi-dori, Chuo-ku, Niigata 951-8510, Japan
}

regenerative medicine for the treatment of liver diseases and IBDs.

In this paper, we review the current status of clinical trials using autologous/allogeneic MSCs in liver diseases

\section{Characteristics of MSCs}

MSCs have recently received attention as potential cell sources for cell therapy due to their ease of expansion and wide range of functions. MSCs can be obtained from not nly bone marrow but also medical wastes, such as adipose ue, umbilical tissue, and dental pulp. MSCs are positive the common markers CD73, CD90, and CD105; hower, they are negative for the endothelial marker CD31 and (4-7]. The expansion of MSCs is relatively easy, and under appropriate condiMSCs are broadly divided into two mechanisms: (1) recruited MSCs differentiate into functional cells to replace damaged cells, permitting the treatment of bone and cartilage damage; and (2) in response to inflammatory cytokines, MSCs help prepare the microenvironment by producing 
immunoregulatory factors that modulate the progression of inflammation by affecting dendritic cells, B cells, $\mathrm{T}$ cells, and macrophages. MSCs also produce a large amount of cytokines, chemokines, and growth factors, including exosomes, which stimulate angiogenesis, prevent apoptosis, block oxidation reactions, promote remodeling of the extracellular matrix (ECM), and induce the differentiation of tissue stem cells $[4,7,8]$. These latter mechanisms can be applied for many diseases, including liver disease and IBSs. Some studies have reported that the effects of MSCs are determined by host conditions, such as inflammation stage and the use of immunosuppressants.

Although the behaviors of MSCs after administration have been analyzed, and some studies have shown that MSCs migrate to the injured site, MSC behaviors in humans have not been fully elucidated. Some studies have reported that MSCs disappear within a few weeks and do not remain long in the target tissue [5]. Recent studies have reported that only culture-conditioned medium or exosomes induce treatment effects, suggesting that the trophic effect is the most important effect of MSCs [9-11]. Another important characteristic of MSCs is that they generally have low immunogenicity. MSCs have no antigen-presenting properties and do not express major histocompatibility complex class II or costimulatory molecules; thus, injection of autologous or allogeneic MSCs has been employed in clinical studies. Allogeneic MSC therapy has the potential to expand MSC therapy to many patients $[4,7]$.

\section{Clinical trials using MSCs}

Since MSCs can be obtained relatively easily and have multiple functions, more than 680 clinical trials are ongoing according to ClinicalTrials.gov (https://clinicaltrials.gov/); most of these studies are phase I or II trials evaluating the use of MSCs in bone/cartilage, heart, neuron, immune/autoimmune, diabetes/kidney, lung, liver, and gastrointestinal fields. These studies aim to elucidate the safety/effectiveness of MSCs in the treatment of various diseases. In liver diseases, 40 trials are registered, most of which target liver cirrhosis or acute liver diseases (Table 1) [12-21]. The MSCs used in clinical trials of the liver are derived from the bone marrow (55\%), umbilical cord tissue (35\%), and adipose tissue (8\%). Approximately $50 \%$ of MSCs are allogeneic. Additionally, while the major administration route is the peripheral blood, approximately $40 \%$ of cases are treated via the hepatic artery, reflecting the fact that hepatologists and radiologists often use catheters to treat hepatocellular carcinoma through the hepatic artery [22, 23] (Fig. 1).

In IBDs, 26 trials are registered (Table 2), 23 of which are investigating the use of MSCs in Crohn's disease (CD), and 3 of which are investigating the use of MSCs in ulcerative colitis (UC) [24-33]. More than $60 \%$ of trials are employing allogeneic MSCs, and in CD, more than $40 \%$ of the trials are evaluating intralesional injection into the fistula, which is the major and refractory complication of CD (Fig. 2).

\section{Clinical trials in liver diseases \\ Background of liver diseases}

Although the liver has high regenerative capacity, acute liver damage caused by viruses, drugs, alcohol, and autoimmune diseases, or chronic liver damage caused by hepatitis $\mathrm{B}$ or $\mathrm{C}$ virus, alcohol, non-alcoholic steatohepatitis (NASH), autoimmune hepatitis, and primary biliary cholangitis often cause liver failure [34]. The liver has a variety of functions, including metabolism of protein, sugar, and fat; detoxification; production of coagulation factors; and production of bile. Thus, during liver failure, several symptoms, including jaundice, edema, ascites, hepatic encephalopathy, and increased bleeding, can appear at the same time, resulting in life-threatening disease. In addition, during liver failure caused by chronic liver disease, accumulated liver fibrosis (i.e., liver cirrhosis) can cause portal hypertension, which often induces the varices, and long-term liver damage can cause gene abnormalities, leading to liver cancers. The ultimate therapy for liver failure is liver transplantation; however, only a small portion of patients with liver failure can receive liver transplantation due to the shortage of donor organs, invasiveness of operations, and economic reasons [35]. Revolutionary treatments, such as interferon-free treatment for hepatitis $\mathrm{C}$ and providing information regarding the importance of the daily lifestyle to prevent alcoholic liver disease and NASH, can potentially decrease the liver diseases; however, unmet needs to treat advanced liver failure will continue.

Advanced acute liver failure and chronic liver failure (liver cirrhosis) can be good targets for cell therapy. Since 2003, Terai et al. initiated autologous bone marrow cell infusion (ABMi) therapy against decompensated liver cirrhosis and confirmed the improvement of liver fibrosis and liver function [36-38]. However, due to the invasiveness of liver transplantation in patients with liver failure, minimally invasive procedures using specific cells, such as MSCs and macrophages [39-41], are now being developed, with a focus on MSCs. In the next section, we will describe recent reported results using MSCs registered at ClinicalTrials.gov.

\section{Effects of MSC therapy in liver disease from published papers}

Animal experiments have shown that MSCs can have antiapoptotic [42] and antioxidant effects in hepatocytes [43], and antifibrotic [44, 45], angiogenic [46], and immunosuppressive effects in T cells, macrophages, and dendritic cells [8]. In human clinical trials, all reports have shown that MSC injection is safe. Although the effects of cell therapy 


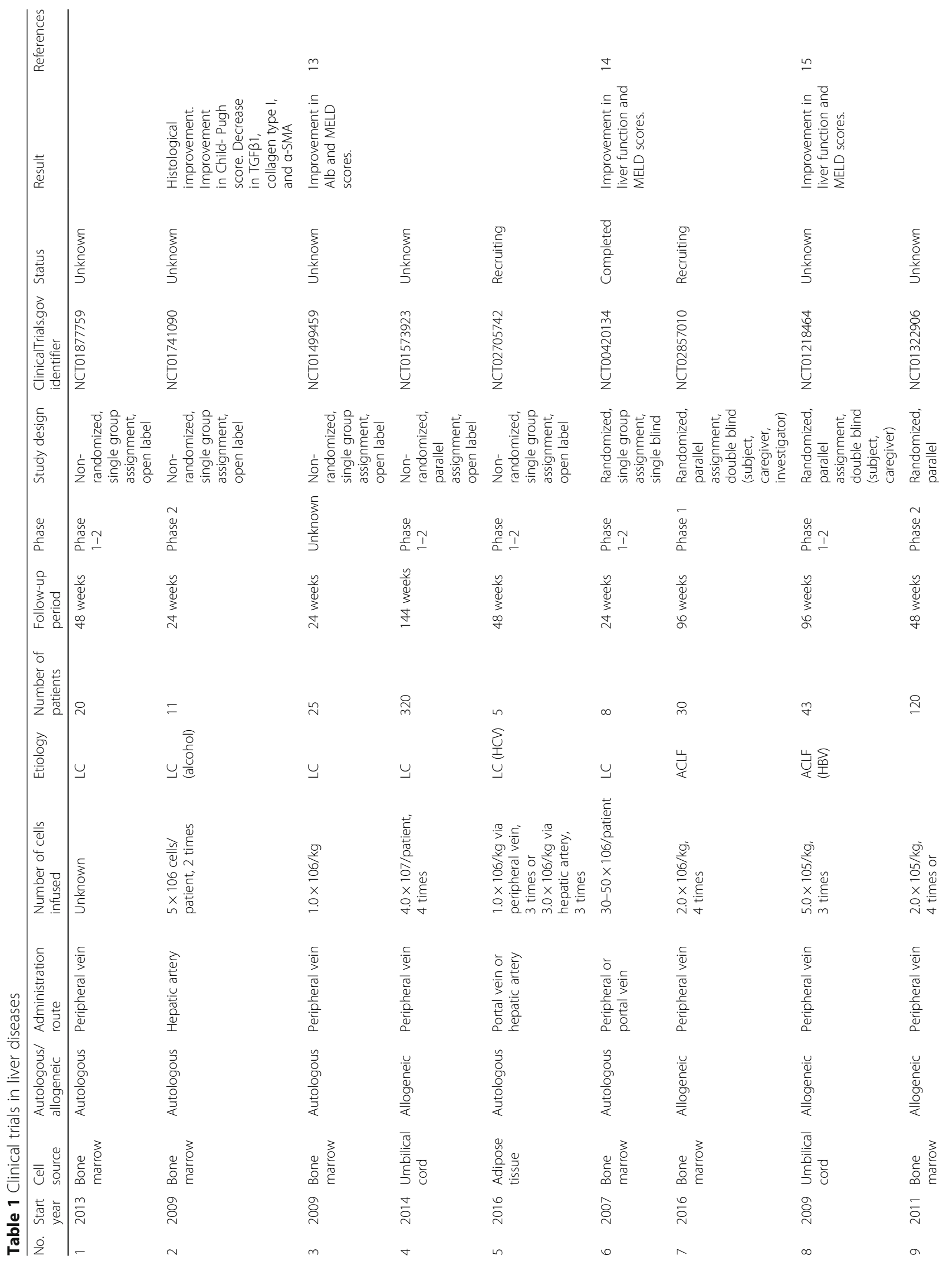




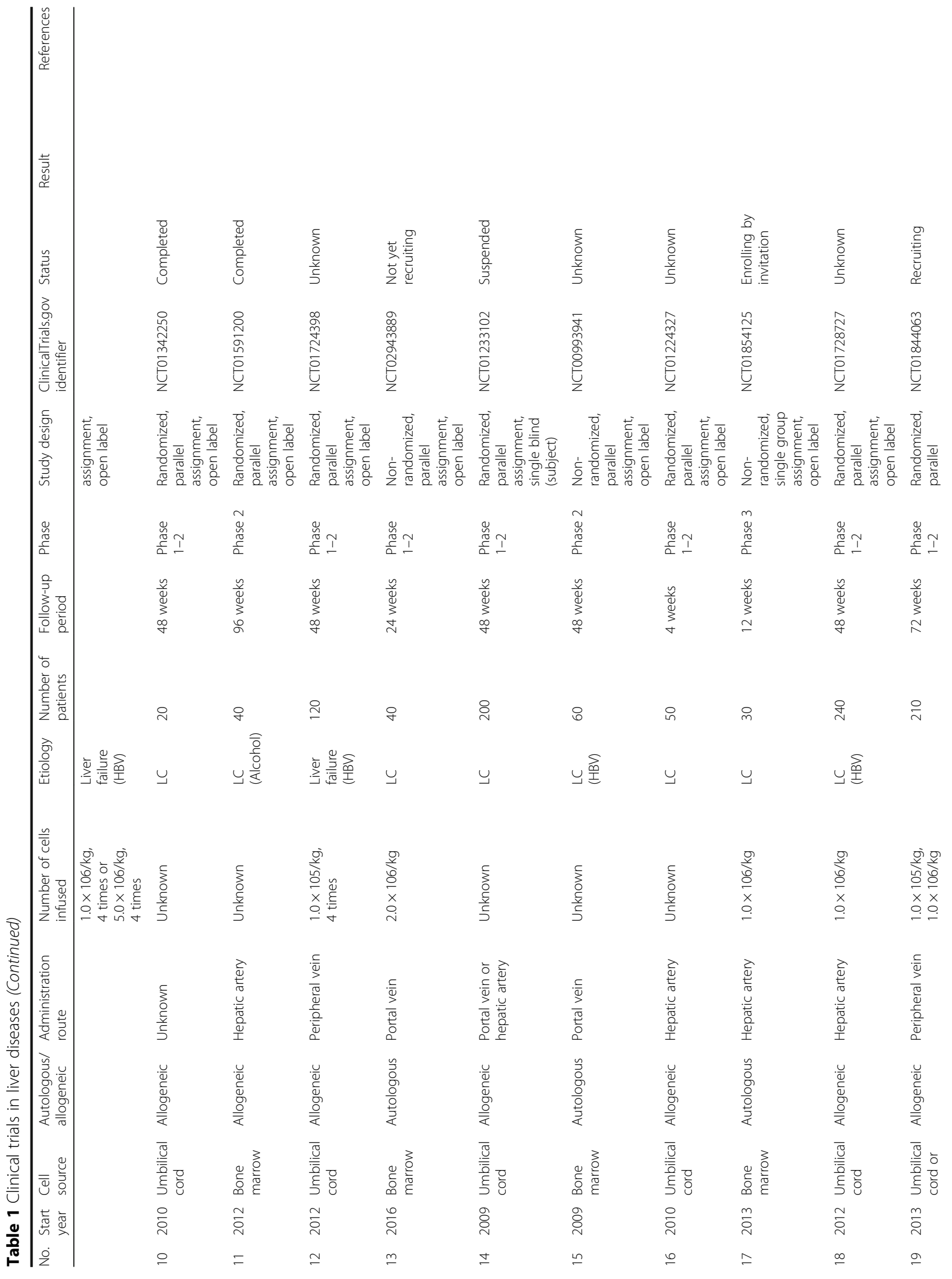


Tsuchiya et al. Inflammation and Regeneration (2017) 37:16

Page 5 of 15

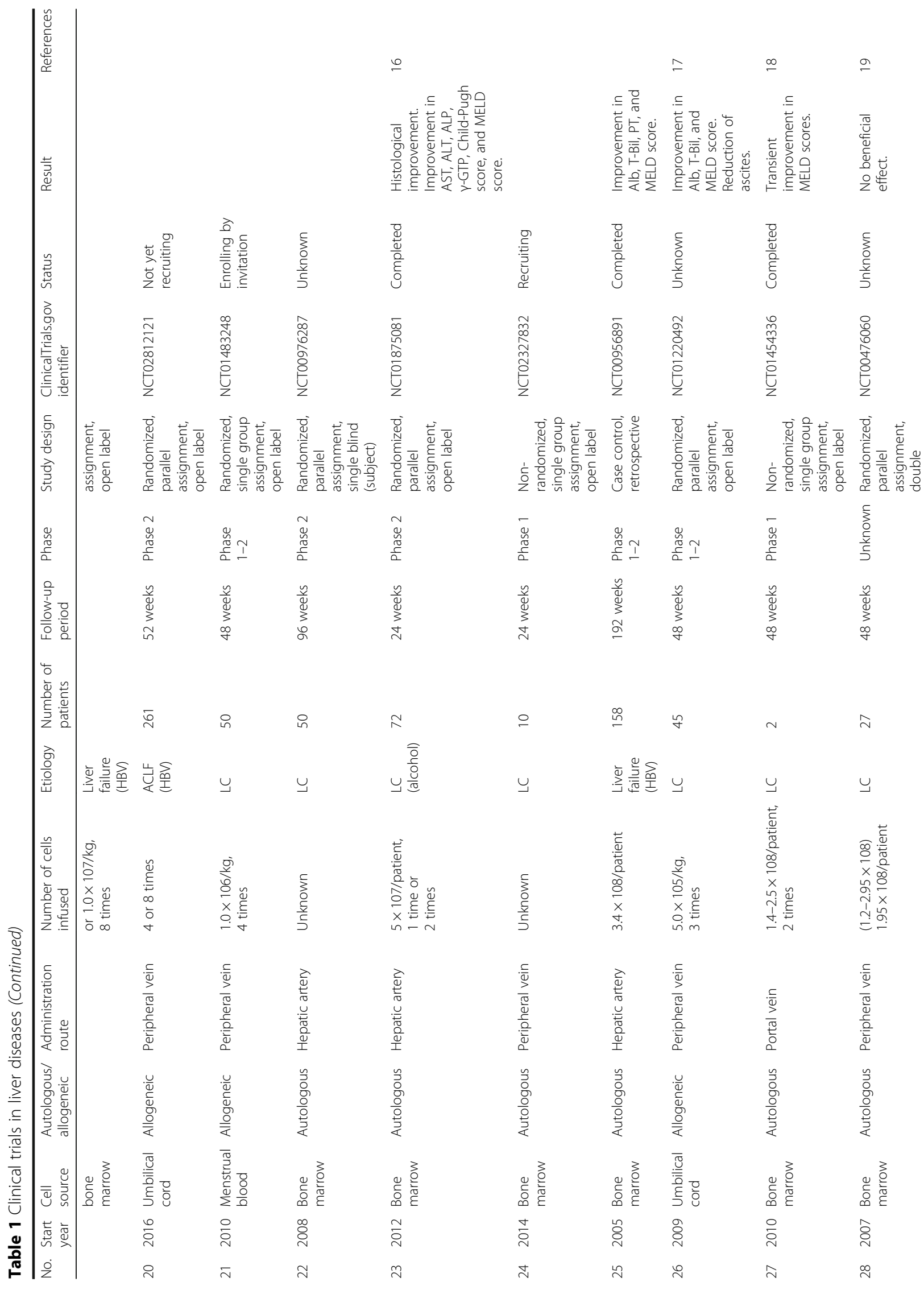


Tsuchiya et al. Inflammation and Regeneration (2017) 37:16

Page 6 of 15

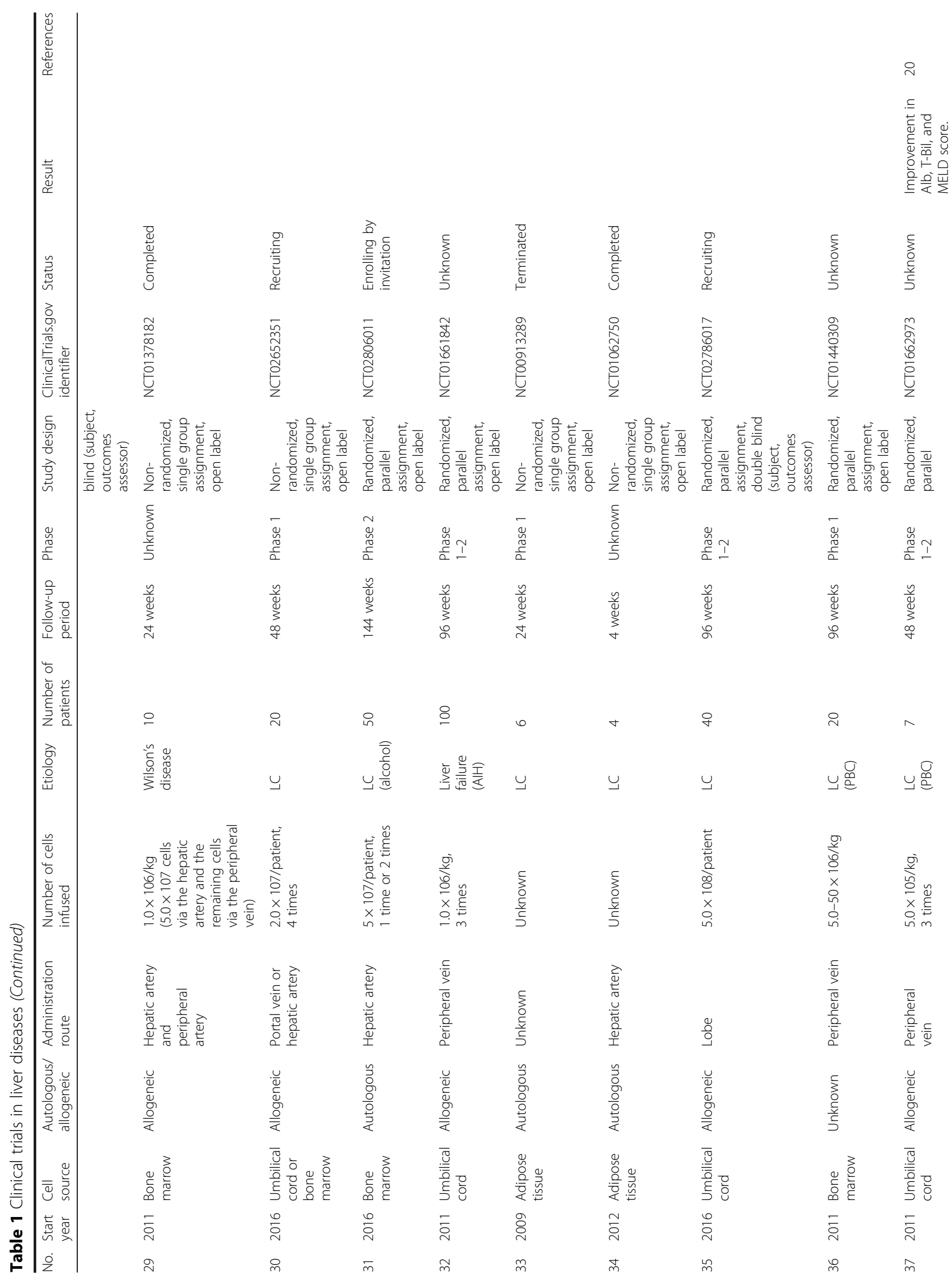


Tsuchiya et al. Inflammation and Regeneration (2017) 37:16

Page 7 of 15

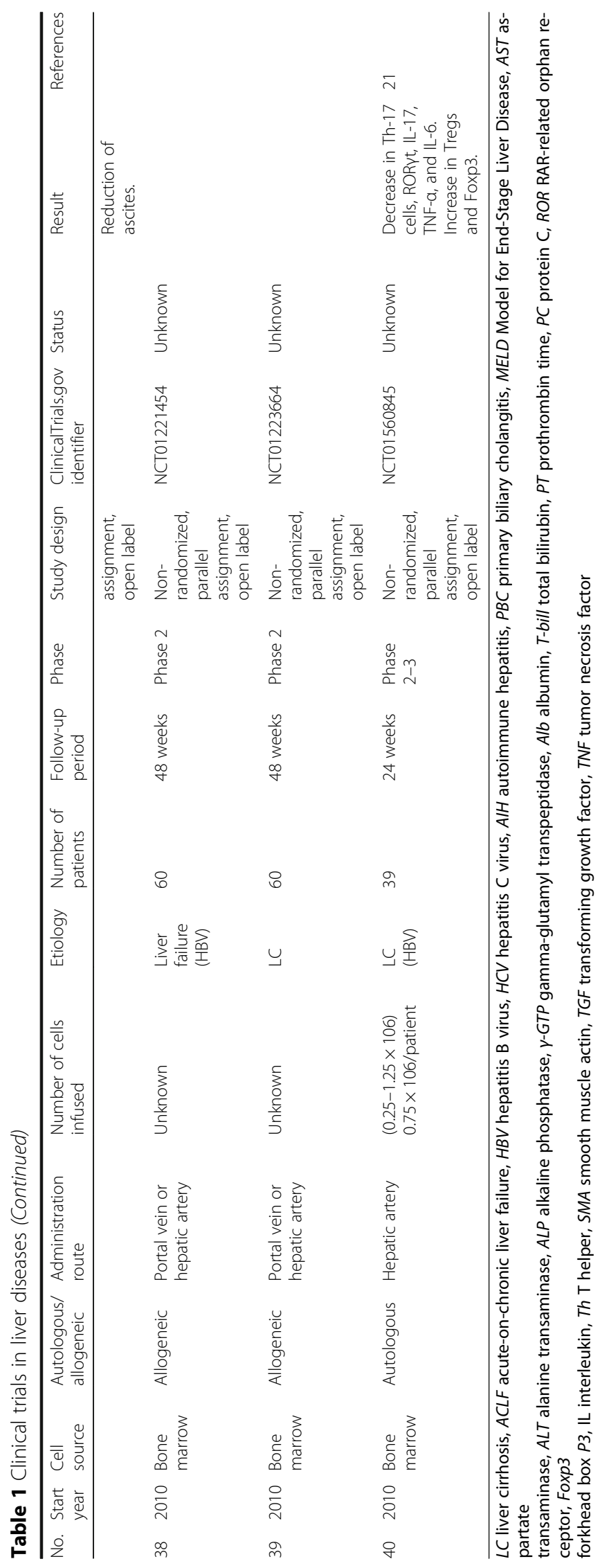




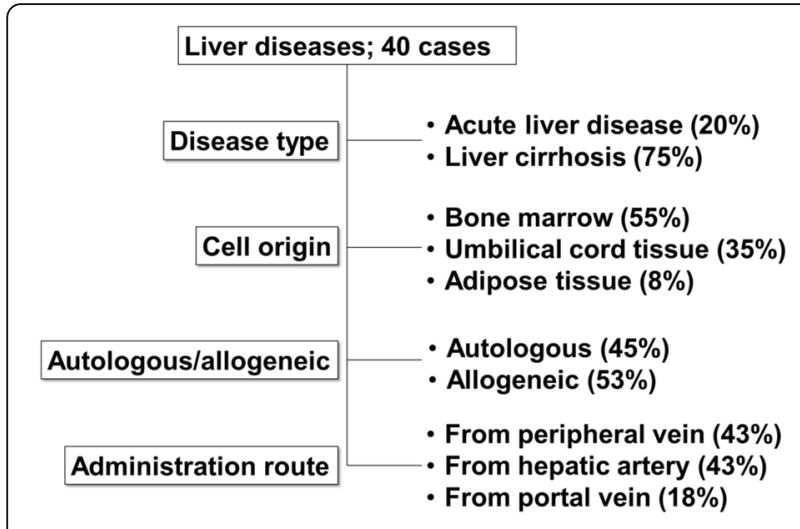

Fig. 1 Summary of clinical trials in liver diseases

are not uniform, the majority of therapies have some beneficial effects; in contrast, in a few reports, treatment effects were not observed. For example, Kantarcioglu et al. [13] and Mohamadnejad et al. [19] injected bone marrowderived MSCs into patients with liver cirrhosis and did not observe treatment effects. However, Kharaziha et al. [14] reported phase I-II clinical trials using autologous bone marrow-derived MSCs against liver cirrhosis with a variety of etiologies, and improvement of liver function was confirmed. Jang et al. and Suk et al. [12, 16] reported a pilot study and a phase II study using autologous bone marrowderived MSCs injected through the hepatic artery against alcoholic liver cirrhosis, and improvement of histological liver fibrosis and liver function was confirmed. Xu et al. [21] reported trials using autologous bone marrow-derived MSCs against hepatitis B virus-associated cirrhosis and confirmed the improvement of liver function, the decrease of Th17 cells, and the increase of regulatory $\mathrm{T}$ cells. Xhang et al. [17] and Wang et al. [20] reported trials using allogeneic umbilical cord-derived MSCs in patients with chronic hepatitis B having decompensated liver cirrhosis and primary biliary cirrhosis, respectively. They confirmed improvement of liver function, particularly reduced ascites and recovery of biliary enzymes, respectively. Shi et al. [15] reported a trial investigating acute or chronic liver failure associated with hepatitis B virus and confirmed that MSCs significantly increased survival rates. From these reports, MSCs appeared to improve liver function; however, additional trials are needed to confirm these effects and to elucidate the mechanisms in more detail.

\section{Clinical trials in IBDs Background of IBDs}

IBDs are chronic inflammatory disorders, including UC and CD. The pathogenesis of IBD is thought to be highly complex due to several factors, such as environmental factors, genetic predisposition, and inflammatory abnormalities [47]. UC is characterized by inflammation of the mucosal membrane of the colon continued from the rectum. Type $2 \mathrm{~T}$ helper cell (Th2) cytokine profile is associated with the pathogenesis of UC. In contrast, CD is a segmental, transluminal disorder that can arise within the entire gastrointestinal tract from the mouth to the anus. Th1 cells are associated with the pathogenesis of CD [48]. Furthermore, a recent report showed that Th17 cells are present in both UC and CD. Thus, mucosal CD4+ T cells are key mediators of the driving response [49]. Macrophages that produce tumor necrosis factor (TNF)- $\alpha$ have also been reported to be relevant in IBD. Imbalances in other cytokines, such as interleukin (IL)-1 $\beta$, IL-6, IL-8, IL-10, IL-12, IL-17, IL-23, and transforming growth factor- $\beta$ (TGF- $\beta$ ), are also detected during diseases [48]. Recent advancements in the development of drugs for IBD include drugs targeting TNF and new candidate drugs, such as antibodies against IL-6 [50] and IL-12/23 [51-53], small molecules including Janus kinase inhibitors [54], antisense oligonucleotides against SMAD7 mRNA [55], and inhibitors of leukocyte trafficking to intestinal sites of inflammation [56, 57]. However, some patients will fail to respond to current medical options, immunosuppressive agents, and anti-TNF biologicals. MSCs may be an effective option in these patients $[9,49]$. In the next section, we will describe recently reported results using MSCs registered in ClinicalTrials.gov.

\section{Effects of MSC therapy in IBD from published papers}

Eight $\mathrm{CD}$ trials and one UC trial have been published in ClinicalTrials.gov. Six papers describing CD are on trials treating fistula, and two papers are trials for luminal CD. Molendijk et al. [25] reported improved healing of refractory perianal fistulas using allogeneic bone marrow-derived MSCs. They administered these allogeneic MSCs locally and concluded that injection of $3 \times 10^{7}$ MSCs appeared to promote the healing of perianal fistula. Panes et al. [31] reported a phase III randomized, double-blind, parallelgroup, placebo-controlled study of complex perianal fistula using expanded allogeneic adipose-derived MSCs and confirmed the safety of the MSCs and the healing effects of MSCs on the fistula. Duijvestein et al. [32] reported a phase I study of refractory luminal CD using autologous bone marrow-derived MSCs and confirmed the safety and feasibility of MSC therapy. Forbes et al. [24] reported a phase II study using allogeneic bone marrow-derived MSCs for luminal CD refractory to biologic therapy. They administered $2 \times 10^{6}$ cells $/ \mathrm{kg}$ weekly for 4 weeks and found that allogeneic MSCs reduced the CD activity index (CDAI) and CD endoscopic index of severity (CDEIS) scores in patients with luminal $\mathrm{CD}$ refractory to biologic therapy. $\mathrm{Hu}$ et al. [33] reported a phase I/II study for severe UC using umbilical cord-derived allogeneic MSCs by combination injection through the peripheral blood and superior mesenteric artery with a 7-day interval. They confirmed the safety of 


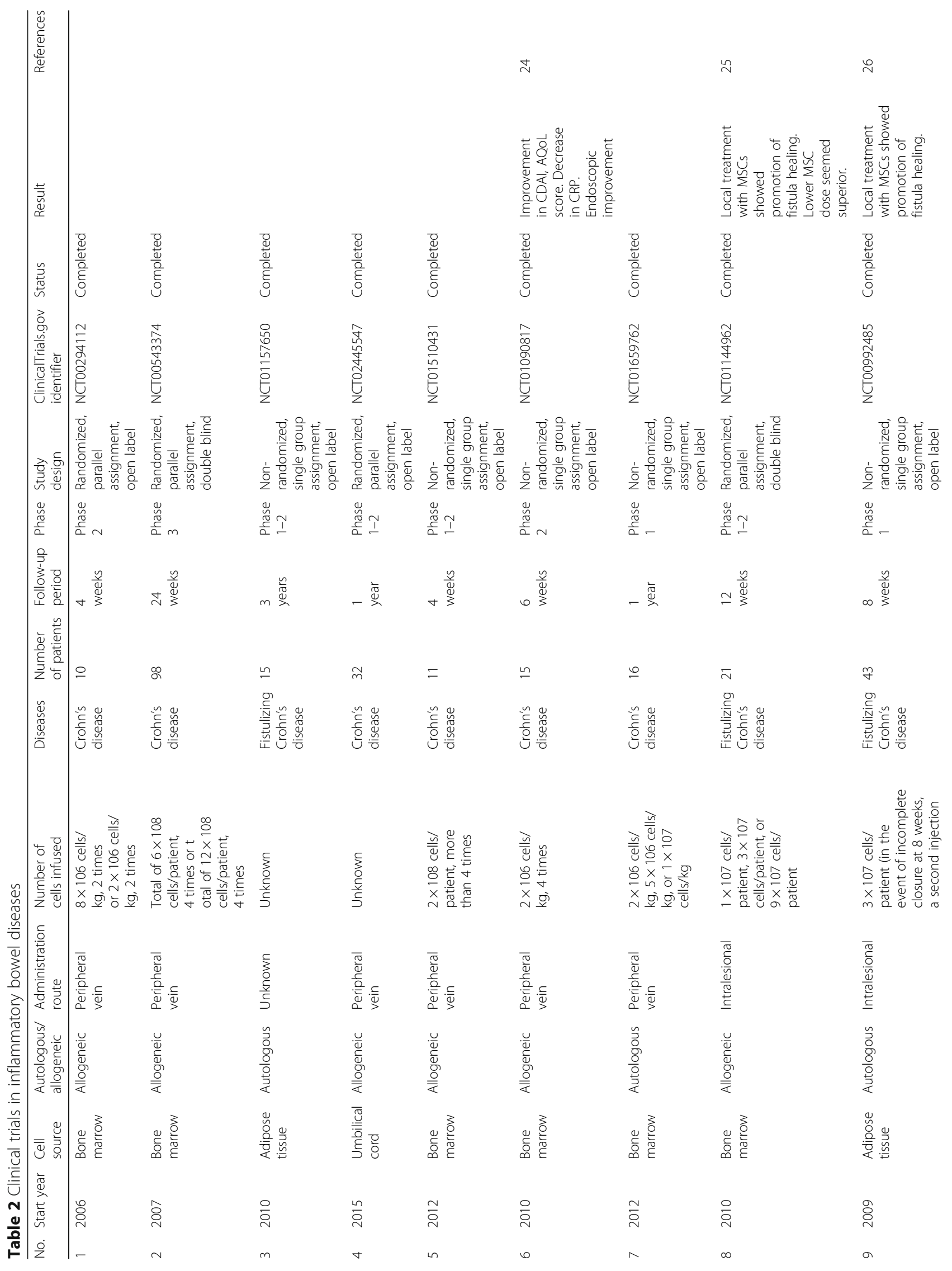




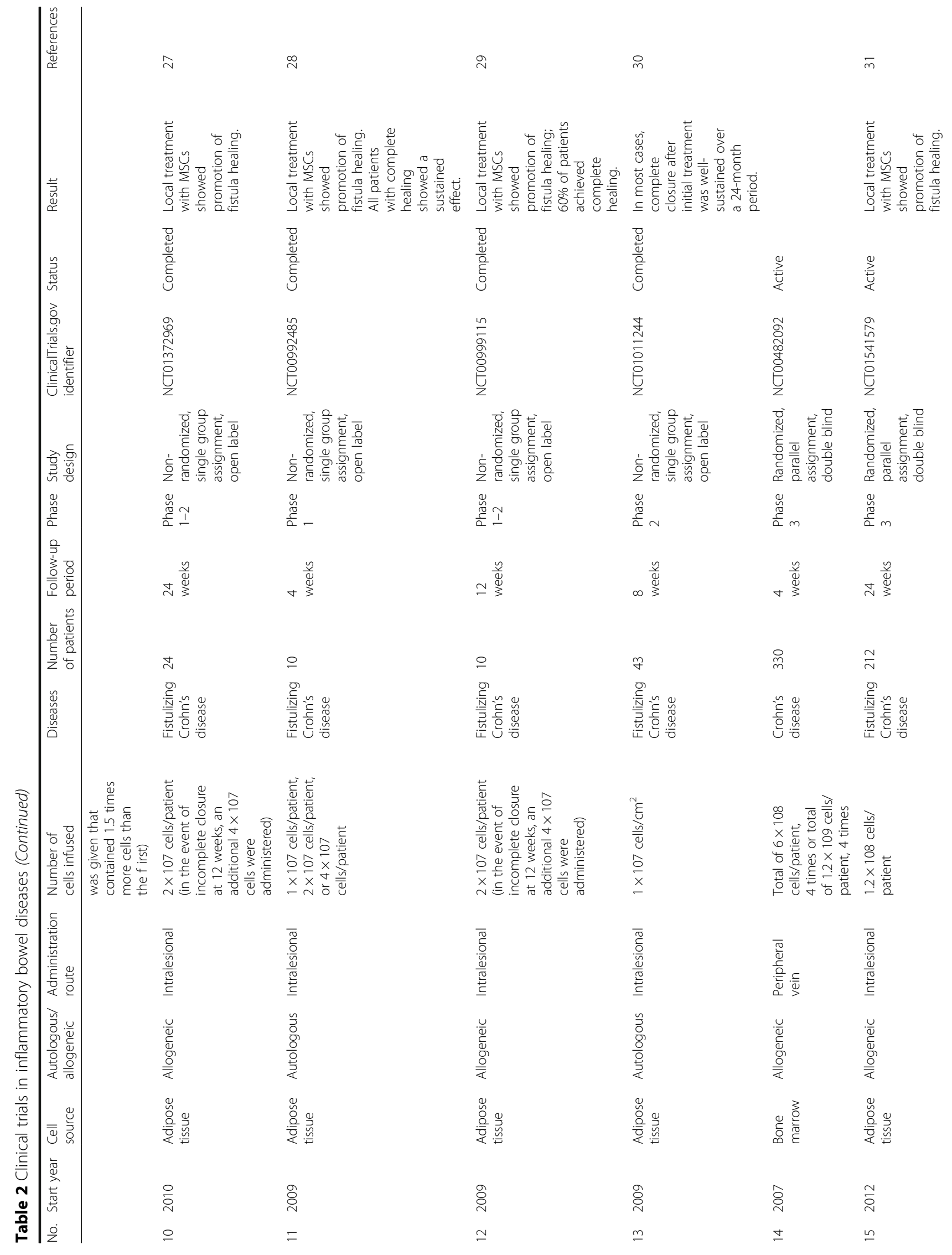




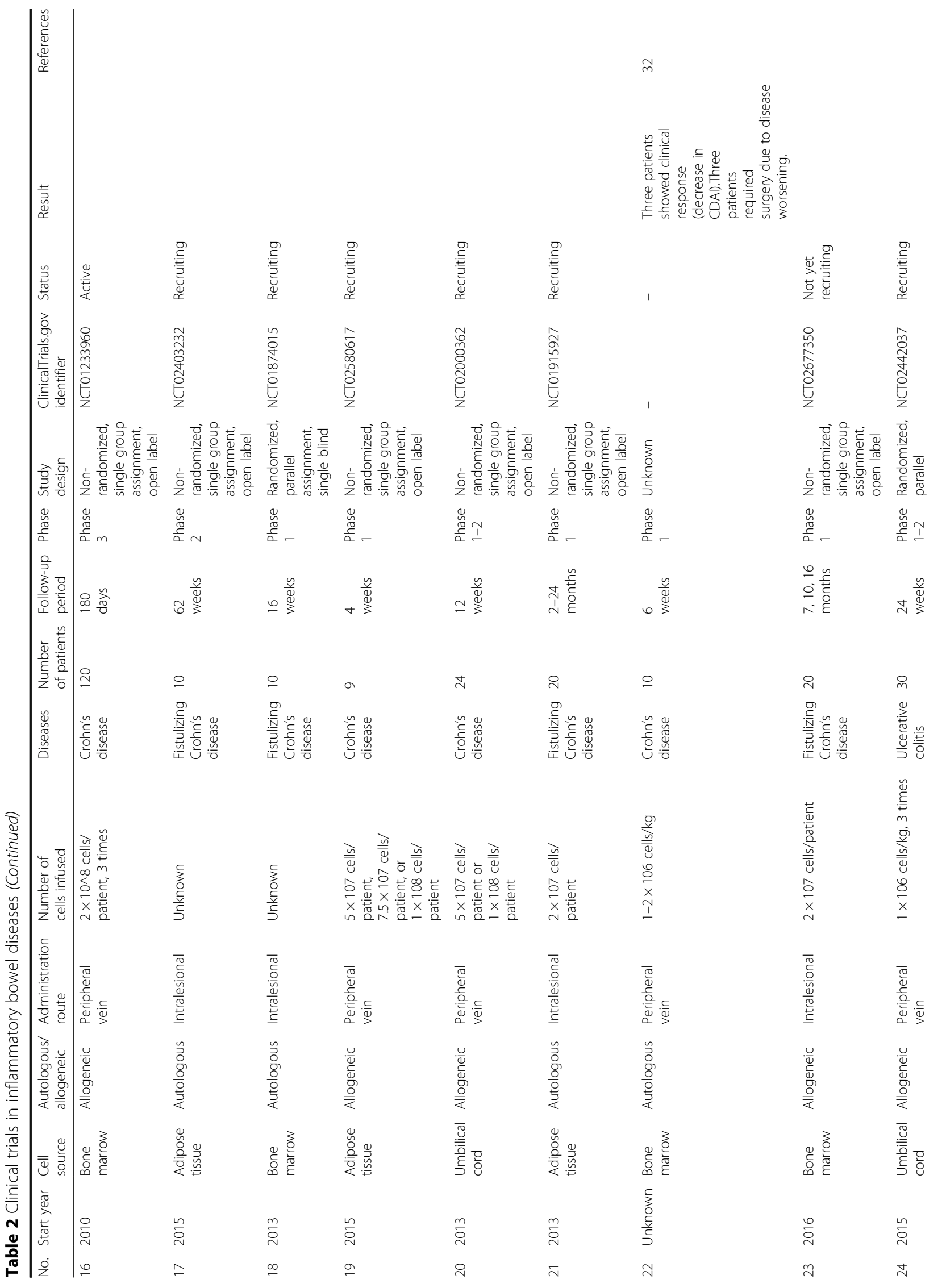




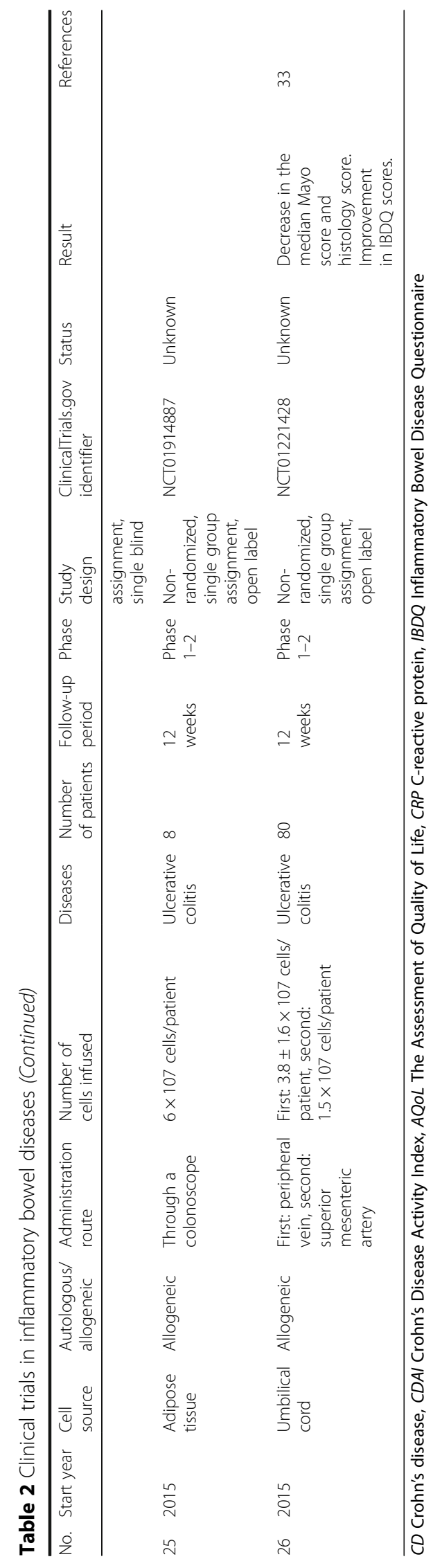




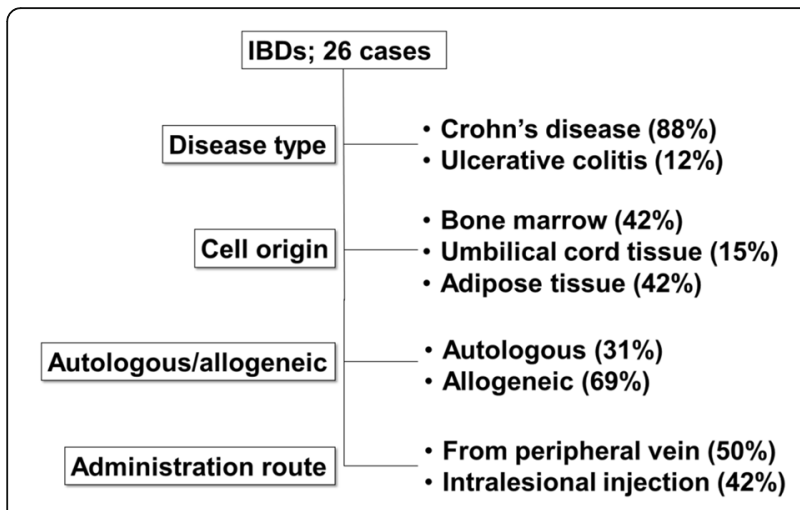

Fig. 2 Summary of clinical trials in inflammatory bowel diseases

MSCs and alleviation of diffuse and deep ulcer formation and severe inflammatory mucosa by MSCs.

\section{Safety of the MSC therapy}

MSC therapy is associated with some concerns, such as adverse events related to infusion, tumor formation during the treatment of liver cirrhosis, and long-term observations of tumor formation. Regarding adverse events related to the infusion, Lalu et al. performed a meta-analysis of the safety of MSCs in clinical trials and showed that autologous and allogeneic MSC therapies were related to transient fever but not infusion toxicity, organ system complications, infection, death, and malignancies (Table 2) [5]. Regarding tumor formation during the treatment of liver cirrhosis, Peng et al. reported that no severe adverse events or no significant differences in tumor formation were detected compared with those in the control group during autologous bone marrow-derived MSC therapy for liver cirrhosis [58]. Regarding long-term observations of tumor formation derived from MSCs, Bahr et al. reported recent autopsy data from patients in a clinical trial of graft-versus-host disease (GvHD) who received MSC therapy between 2002 and 2007 and revealed no ectopic tissues, neoplasms, or donor-derived DNA [6].

\section{Conclusions}

Many clinical trials of autologous and allogeneic MSCs have aimed to elucidate the effects and mechanisms of MSCs. MSCs can expand easily and can be obtained from medical waste, suggesting their applications in regenerative medicine for the treatment of liver diseases and IBDs. Recently, limitations of MSCs have been reported. For example, therapeutic effects were not long term and were affected by inflammatory condition $[59,60]$. Thus, the results of ongoing clinical studies will be expected to provide further insights.

\section{Abbreviations}

ABMi: Autologous bone marrow cell infusion; CD: Crohn's disease; CD

CDEIS: Endoscopic index of severity; CDAl: CD activity index; ECM: Extracellular matrix; GvHD: Graft-versus-host disease; IBD: Inflammatory bowel disease; IL: Interleukin; MSCs: Mesenchymal stem cells; NASH: Non-alcoholic steatohepatitis; TGF- $\beta$ : Transforming growth factor; TNF: Tumor necrosis factor; UC: Ulcerative colitis

\section{Acknowledgements}

The authors thank Dr. Takayuki Watanabe and Dr. Suguru Takeuchi for their cooperation.

\section{Funding}

This work was supported by a Grant-in-Aid for Scientific Research (B) (26293175) from the Ministry of Education, Science, Technology, Sports, and Culture of Japan and by Highway Program for Realization of Regenerative Medicine from Japan Agency for Medical Research and Development, AMED.

Availability of data and materials

There is no available data except the manuscript and tables.

\section{Author's contributions}

AT and ST wrote the paper. YK, SI, SS, YW, and YK prepared the data and made the tables. All authors read and approved the final manuscript.

\section{Competing interests}

The authors declare that they have no competing interests.

Consent for publication

All authors agreed to publish this work.

Ethics approval and consent to participate

There is no ethics approval and consent to participate due to review.

\section{Publisher's Note}

Springer Nature remains neutral with regard to jurisdictional claims in published maps and institutional affiliations.

Received: 30 January 2017 Accepted: 13 April 2017

Published online: 03 July 2017

\section{References}

1. Malfertheiner P, Megraud F, O'Morain CA, et al. Management of Helicobacter pylori infection-the Maastricht V/Florence Consensus Report. Gut. 2017;66:6-30.

2. Goldberg D, Ditah IC, Saeian K, et al. Changes in the prevalence of hepatitis $C$ virus infection, non-alcoholic steatohepatitis, and alcoholic liver disease among patients with cirrhosis or liver failure on the waitlist for liver transplantation. Gastroenterology. 2017;152(5):1090-1099.e1.

3. Gecse KB, Lakatos PL. IBD in 2016: biologicals and biosimilars in IBD - the road to personalized treatment. Nat Rev Gastroenterol Hepatol. 2017;14(2): 74-76.

4. Trounson A, McDonald C. Stem cell therapies in clinical trials: progress and challenges. Cell Stem Cell. 2015;17:11-22.

5. Lalu MM, McIntyre L, Pugliese C, et al. Safety of cell therapy with mesenchymal stromal cells (SafeCell): a systematic review and meta-analysis of clinical trials. PLoS One. 2012;7:e47559.

6. Owen A, Newsome PN. Mesenchymal stromal cell therapy in liver disease: opportunities and lessons to be learnt? Am J Physiol Gastrointest Liver Physiol. 2015;309:G791-800.

7. Terai S, Tsuchiya A. Status of and candidates for cell therapy in liver cirrhosis: overcoming the "point of no return" in advanced liver cirrhosis. J Gastroenterol. 2017:52(2):129-40.

8. Wang Y, Chen X, Cao W, et al. Plasticity of mesenchymal stem cells in immunomodulation: pathological and therapeutic implications. Nat Immunol. 2014;15:1009-16.

9. Hawkey CJ, Hommes DW. Is stem cell therapy ready for prime time in treatment of inflammatory bowel diseases? Gastroenterology. 2017;152:389-97. e2.

10. Katsuda T, Kosaka N, Takeshita F, et al. The therapeutic potential of mesenchymal stem cell-derived extracellular vesicles. Proteomics. 2013;13:1637-53.

11. Li T, Yan Y, Wang B, et al. Exosomes derived from human umbilical cord mesenchymal stem cells alleviate liver fibrosis. Stem Cells Dev. 2013;22:845-54 
12. Jang YO, Kim YJ, Baik SK, et al. Histological improvement following administration of autologous bone marrow-derived mesenchymal stem cells for alcoholic cirrhosis: a pilot study. Liver Int. 2014;34:33-41.

13. Kantarcioglu M, Demirci H, Avcu F, et al. Efficacy of autologous mesenchymal stem cell transplantation in patients with liver cirrhosis. Turk J Gastroenterol. 2015;26:244-50.

14. Kharaziha P, Hellstrom PM, Noorinayer B, et al. Improvement of liver function in liver cirrhosis patients after autologous mesenchymal stem cell injection: a phase I-II clinical trial. Eur J Gastroenterol Hepatol. 2009;21:1199-205.

15. Shi $M, Z$ hang $Z, X u R$, et al. Human mesenchymal stem cell transfusion is safe and improves liver function in acute-on-chronic liver failure patients. Stem Cells Transl Med. 2012;1:725-31.

16. Suk KT, Yoon JH, Kim MY, et al. Transplantation with autologous bone marrowderived mesenchymal stem cells for alcoholic cirrhosis: phase 2 trial. Hepatology. 2016;64(6):2185-97.

17. Zhang $Z$, Lin $H$, Shi M, et al. Human umbilical cord mesenchymal stem cells improve liver function and ascites in decompensated liver cirrhosis patients. J Gastroenterol Hepatol. 2012;27 Suppl 2:112-20.

18. Vosough M, Moossavi S, Mardpour S, et al. Repeated intraportal injection of mesenchymal stem cells in combination with pioglitazone in patients with compensated cirrhosis: a clinical report of two cases. Arch Iran Med. 2016:19:131-6

19. Mohamadnejad M, Alimoghaddam K, Bagheri M, et al. Randomized placebocontrolled trial of mesenchymal stem cell transplantation in decompensated cirrhosis. Liver Int. 2013;33:1490-6.

20. Wang L, Li J, Liu H, et al. Pilot study of umbilical cord-derived mesenchymal stem cell transfusion in patients with primary biliary cirrhosis. J Gastroenterol Hepatol. 2013;28 Suppl 1:85-92

21. Xu L, Gong Y, Wang B, et al. Randomized trial of autologous bone marrow mesenchymal stem cells transplantation for hepatitis B virus cirrhosis: regulation of Treg/Th17 cells. J Gastroenterol Hepatol. 2014;29:1620-8.

22. Tsuchiya A, Kubota T, Takizawa K, et al. Successful treatment in a case of massive hepatocellular carcinoma with paraneoplastic syndrome. Case Rep Gastroenterol. 2009;3:105-10.

23. Lencioni $\mathrm{R}$, de Baere $\mathrm{T}$, Soulen $\mathrm{MC}$, et al. Lipiodol transarterial chemoembolization for hepatocellular carcinoma: a systematic review of efficacy and safety data. Hepatology. 2016;64:106-16.

24. Forbes GM, Sturm MJ, Leong RW, et al. A phase 2 study of allogeneic mesenchymal stromal cells for luminal Crohn's disease refractory to biologic therapy. Clin Gastroenterol Hepatol. 2014;12:64-71.

25. Molendijk I, Bonsing BA, Roelofs $H$, et al. Allogeneic bone marrow-derived mesenchymal stromal cells promote healing of refractory perianal fistulas in patients With Crohn's disease. Gastroenterology. 2015;149:918-27. e6.

26. Lee WY, Park KJ, Cho YB, et al. Autologous adipose tissue-derived stem cells treatment demonstrated favorable and sustainable therapeutic effect for Crohn's fistula. Stem Cells. 2013;31:2575-81.

27. de la Portilla F, Alba F, Garcia-Olmo D, et al. Expanded allogeneic adiposederived stem cells (eASCs) for the treatment of complex perianal fistula in Crohn's disease: results from a multicenter phase I/lla clinical trial. Int J Colorectal Dis. 2013;28:313-23.

28. Cho YB, Lee WY, Park KJ, et al. Autologous adipose tissue-derived stem cells for the treatment of Crohn's fistula: a phase I clinical study. Cell Transplant. 2013;22:279-85.

29. Garcia-Arranz M, Dolores Herreros M, Gonzalez-Gomez C, et al. Treatment of Crohn's-related rectovaginal fistula with allogeneic expanded-adipose derived stem cells: a phase I-Ila Clinical Trial. Stem Cells Transl Med. 2016; 5(11):1441-46.

30. Cho YB, Park KJ, Yoon SN, et al. Long-term results of adipose-derived stem cell therapy for the treatment of Crohn's fistula. Stem Cells Transl Med. 2015:4:532-7.

31. Panes J, Garcia-Olmo D, Van Assche G, et al. Expanded allogeneic adiposederived mesenchymal stem cells (Cx601) for complex perianal fistulas in Crohn's disease: a phase 3 randomised, double-blind controlled trial. Lancet. 2016;388:1281-90.

32. Duijvestein $M$, Vos AC, Roelofs $H$, et al. Autologous bone marrow-derived mesenchymal stromal cell treatment for refractory luminal Crohn's disease: results of a phase I study. Gut. 2010;59:1662-9.

33. $\mathrm{Hu}$ J, Zhao G, Zhang L, et al. Safety and therapeutic effect of mesenchymal stem cell infusion on moderate to severe ulcerative colitis. Exp Ther Med. 2016;12:2983-9.
34. Tsuchiya A, Kamimura H, Takamura M, et al. Clinicopathological analysis of CD133 and NCAM human hepatic stem/progenitor cells in damaged livers and hepatocellular carcinomas. Hepatol Res. 2009;39:1080-90.

35. Fayek SA, Quintini C, Chavin KD, et al. The current state of liver transplantation in the United States: perspective from American Society of Transplant Surgeons (ASTS) Scientific Studies Committee and Endorsed by ASTS Council. Am J Transplant. 2016;16:3093-104.

36. Terai S, Ishikawa T, Omori $\mathrm{K}$, et al. Improved liver function in patients with liver cirrhosis after autologous bone marrow cell infusion therapy. Stem Cells. 2006;24:2292-8.

37. Kim JK, Park YN, Kim JS, et al. Autologous bone marrow infusion activates the progenitor cell compartment in patients with advanced liver cirrhosis. Cell Transplant. 2010;19:1237-46.

38. Saito T, Okumoto K, Haga $\mathrm{H}$, et al. Potential therapeutic application of intravenous autologous bone marrow infusion in patients with alcoholic liver cirrhosis. Stem Cells Dev. 2011;20:1503-10.

39. Thomas JA, Pope C, Wojtacha D, et al. Macrophage therapy for murine liver fibrosis recruits host effector cells improving fibrosis, regeneration, and function. Hepatology. 2011;53:2003-15.

40. Forbes SJ, Rosenthal N. Preparing the ground for tissue regeneration: from mechanism to therapy. Nat Med. 2014;20:857-69.

41. Moore JK, Mackinnon AC, Wojtacha D, et al. Phenotypic and functional characterization of macrophages with therapeutic potential generated from human cirrhotic monocytes in a cohort study. Cytotherapy. 2015;17:1604-16.

42. Jin S, Li H, Han M, et al. Mesenchymal stem cells with enhanced BCl-2 expression promote liver recovery in a rat model of hepatic cirrhosis. Cell Physiol Biochem. 2016;40:1117-28.

43. Quintanilha LF, Takami T, Hirose Y, et al. Canine mesenchymal stem cells show antioxidant properties against thioacetamide-induced liver injury in vitro and in vivo. Hepatol Res. 2014;44:E206-17.

44. Volarevic V, Nurkovic J, Arsenijevic N, et al. Concise review: therapeutic potential of mesenchymal stem cells for the treatment of acute liver failure and cirrhosis. Stem Cells. 2014;32:2818-23.

45. Dai LJ, Li HY, Guan LX, et al. The therapeutic potential of bone marrowderived mesenchymal stem cells on hepatic cirrhosis. Stem Cell Res. 2009;2:16-25

46. Xia X, Tao Q, Ma Q, et al. Growth hormone-releasing hormone and its analogues: significance for MSCs-mediated angiogenesis. Stem Cells Int. 2016;2016:8737589.

47. Nagaishi K, Arimura Y, Fujimiya M. Stem cell therapy for inflammatory bowe disease. J Gastroenterol. 2015;50:280-6.

48. Coskun $\mathrm{M}$, Vermeire $\mathrm{S}$, Nielsen $\mathrm{OH}$. Novel targeted therapies for inflammatory bowel disease. Trends Pharmacol Sci. 2017;38(2):127-42.

49. Gregoire C, Lechanteur C, Briquet A, et al. Review article: mesenchymal stromal cell therapy for inflammatory bowel diseases. Aliment Pharmacol Ther. 2017:45:205-21.

50. Ito H, Takazoe M, Fukuda $Y$, et al. A pilot randomized trial of a human anti-interleukin-6 receptor monoclonal antibody in active Crohn's disease. Gastroenterology. 2004;126:989-96. discussion 947.

51. Sandborn WJ, Feagan BG, Fedorak RN, et al. A randomized trial of Ustekinumab, a human interleukin-12/23 monoclonal antibody, in patients with moderate-tosevere Crohn's disease. Gastroenterology. 2008;135:1130-41.

52. Sandborn WJ, Gasink C, Gao LL, et al. Ustekinumab induction and maintenance therapy in refractory Crohn's disease. N Engl J Med. 2012;367:1519-28.

53. Sandborn W, Gasink C, Blank M, et al. O-001 A multicenter, double-blind, placebo-controlled phase3 study of Ustekinumab, a human IL-12/23P40 $\mathrm{mAB}$, in moderate-service Crohn's disease refractory to anti-TFNalpha: UNITI1. Inflamm Bowel Dis. 2016;22 Suppl 1:S1.

54. Van Rompaey L, Galien R, van der Aar EM, et al. Preclinical characterization of GLPG0634, a selective inhibitor of JAK1, for the treatment of inflammatory diseases. J Immunol. 2013;191:3568-77.

55. Monteleone G, Neurath MF, Ardizzone S, et al. Mongersen, an oral SMAD7 antisense oligonucleotide, and Crohn's disease. N Engl J Med. 2015;372:1104-13.

56. Feagan $B G$, Rutgeerts $P$, Sands $B E$, et al. Vedolizumab as induction and maintenance therapy for ulcerative colitis. N Engl J Med. 2013;369:699-710

57. Sandborn WJ, Feagan BG, Rutgeerts $P$, et al. Vedolizumab as induction and maintenance therapy for Crohn's disease. N Engl J Med. 2013;369:711-21. 
58. Peng L, Xie DY, Lin BL, et al. Autologous bone marrow mesenchymal stem cell transplantation in liver failure patients caused by hepatitis B: short-term and long-term outcomes. Hepatology. 2011;54:820-8.

59. Dave M, Jaiswal P, Cominelli F. Mesenchymal stem/stromal cell therapy for inflammatory bowel disease: an updated review with maintenance of remission. Curr Opin Gastroenterol. 2017;33:59-68.

60. Kim N, Cho SG. New strategies for overcoming limitations of mesenchymal stem cell-based immune modulation. Int J Stem Cells. 2015;8:54-68.

Submit your next manuscript to BioMed Central and we will help you at every step:

- We accept pre-submission inquiries

- Our selector tool helps you to find the most relevant journal

- We provide round the clock customer support

- Convenient online submission

- Thorough peer review

- Inclusion in PubMed and all major indexing services

- Maximum visibility for your research

Submit your manuscript at www.biomedcentral.com/submit 